\title{
Subgroups of musculoskeletal pain patients and their psychobiological patterns - The LOGIN study protocol
}

Andreas Gerhardt", Mechthild Hartmann, Jonas Tesarz, Susanne Janke, Sabine Leisner, Günter Seidler and Wolfgang Eich

\begin{abstract}
Background: Pain conditions of the musculoskeletal system are very common and have tremendous socioeconomic impact. Despite its high prevalence, musculoskeletal pain remains poorly understood and predominantly non-specifically and insufficiently treated.

The group of chronic musculoskeletal pain patients is supposed to be heterogeneous, due to a multitude of mechanisms involved in chronic pain. Psychological variables, psychophysiological processes, and neuroendocrine alterations are expected to be involved. Thus far, studies on musculoskeletal pain have predominantly focused on the general aspects of pain processing, thus neglecting the heterogeneity of patients with musculoskeletal pain. Consequently, there is a need for studies that comprise a multitude of mechanisms that are potentially involved in the chronicity and spread of pain. This need might foster research and facilitate a better pathophysiological understanding of the condition, thereby promoting the development of specific mechanism-based treatments for chronic pain. Therefore, the objectives of this study are as follows: 1) identify and describe subgroups of patients with musculoskeletal pain with regard to clinical manifestations (including mental co-morbidity) and 2) investigate whether distinct sensory profiles or 3) distinct plasma levels of pain-related parameters due to different underlying mechanisms can be distinguished in various subgroups of pain patients.
\end{abstract}

Methods/Design: We will examine a population-based chronic pain sample $(n=100)$, a clinical tertiary care sample $(n=100)$ and pain-free patients with depression or post-traumatic stress disorder and pain-free healthy controls (each $n=30$, respectively). The samples will be pain localisation matched by sex and age to the population-based sample. Patients will undergo physical examination and thorough assessments of mental co-morbidity (including psychological trauma), perceptual and central sensitisation (quantitative sensory testing), descending inhibition (conditioned pain modulation, the diffuse noxious inhibitory control-like effect), as well as measurement of the plasma levels of nerve growth factor and endocannabinoids.

Discussion: The identification of the underlying pathophysiologic mechanisms in different subgroups of chronic musculoskeletal pain patients will contribute to a mechanism-based subgroup classification. This will foster the development of mechanism-based treatments and holds promise to treat patients more sufficient.

Keywords: Chronic non-specific musculoskeletal pain, Endocannabinoids, Mental comorbidity, Pain drawing, Pain extent, Quantitative sensory testing, Mechanism-based, Subgroup classification, Nerve growth factor, Trauma

\footnotetext{
* Correspondence: andreas.gerhardt@med.uni-heidelberg.de

Department of General Internal Medicine and Psychosomatics, University

Hospital Heidelberg, Im Neuenheimer Feld 410, D-69120, Heidelberg,

Germany
}

\section{Biomed Central}

(c) 2012 Gerhardt et al.; licensee BioMed Central Ltd. This is an Open Access article distributed under the terms of the Creative Commons Attribution License (http://creativecommons.org/licenses/by/2.0), which permits unrestricted use, distribution, and reproduction in any medium, provided the original work is properly cited. 


\section{Background}

Chronic pain conditions of the musculoskeletal system are common and of high socioeconomic relevance [1-4]. This is especially true for pain conditions with widely unknown pathogeneses, such as non-specific chronic back pain (CBP), chronic widespread pain (CWP), and fibromyalgia syndrome (FMS). In addition, the prevalence of these conditions and the demand for consultation and treatment have increased over recent years $[5,6]$, which results in high direct and indirect costs $[1,3,7,8]$.

However, therapeutic approaches in chronic musculoskeletal pain patients are often of minor success [9-16]. This is likely because the aetiology and pathogenesis of chronic musculoskeletal pain are still widely unknown. As a result, treatment for this condition involves predominantly unspecific interventions, although the group of chronic musculoskeletal pain patients is believed to be heterogeneous $[17,18]$. Differences in response to the same treatment in patients with the same disease could be explained by different underlying mechanisms contributing to the generation and maintenance of pain $[19,20]$. The situation is complicated by the finding that the same disease can derive from various pathophysiological mechanisms. Conversely, the same pathophysiological mechanism may be of interest in distinct diseases [20].

The heterogeneity is supported by strong hints that subgroups exist that differ in terms of aetiopathology, clinical symptomatology, and psychophysiological patterns. A recent study revealed distinct somatosensory profiles in CBP and FMS: FMS patients showed increased sensitivity for different pain modalities in all measured body areas, which suggests central disinhibition (or a deficient pain inhibitory system) as a potential mechanism. CBP subjects, in contrast, exhibited localised alterations within the affected segment. Such alterations may be due to peripheral sensitisation [21]. This finding is in accordance with the main hypothesis of a mechanism-based diagnosis in chronic pain syndromes, which proposes that defined symptoms and signs reflect possible underlying neurobiological pain mechanisms [19,22]. Consequently, these subgroups should be treated with specific mechanism-based approaches, but to date, they have been treated with the same non-specific multimodal treatment programs. Therefore, the assessment of chronic pain and research identifying various factors associated with the development, maintenance, and spread of chronic pain, including their neurobiological correlates, is highly relevant.

Chronic pain has been found to be associated with a higher prevalence of mental co-morbidity. Patients with CBP [23,24], CWP [25], and FMS [26] suffer from mental disorders significantly more often than pain-free controls. This finding is especially true for anxiety disorders and mood disorders, which were found to have prevalence rates of $20.9 \%$ and $12.7 \%$, respectively, in a population-based sample of patients with chronic back pain [23]. Of further interest is the role of psychological trauma, which has been neglected in previous research. Traumatic events have higher prevalence rates in patients with pain compared to pain-free controls or patients with other diseases [27-29]. Concerning traumatic experiences, it was suggested that multiple traumas have a cumulative effect on physical health, including back pain and that the impact of the trauma on health may be independent of post-traumatic stress disorder (PTSD) symptomatology $[30,31]$.

The assessment of chronic pain and mental comorbidity on a psychobiological basis may detect common underlying pathophysiological changes. With regard to pain processing there are studies that suggest a role for central disinhibition mechanisms in depression and, to a lower extent, in patients with FMS compared to healthy controls [32]. Alterations in pain processing among patients with depression or FMS were reported previously, but this study found that hyperalgesia was more pronounced in patients with FMS than in those with depression [33]. In patients with FMS with comorbid depression or anxiety, pain processing was not altered in comparison to patients with FMS alone [34]. Thus there seems to be an association of chronic pain or depression with altered pain processing, although chronic pain and comorbid depression did not interact with pain processing.

In regard to anxiety disorders and the neglected role of trauma, a study by Defrin et al. described a unique sensory profile of hyposensitivity to non-noxious stimuli, accompanied by hypoalgesia to at-pain-threshold noxious stimuli and hyper-reactivity to suprathreshold noxious stimuli in patients with PTSD and chronic pain compared with healthy controls [35].

This pattern clearly differs from other patient groups with chronic pain, such as those with fibromyalgia, who tend to exhibit pain hypersensitivity $[21,36]$, and from alterations in PTSD, in which context a decreased sensitivity to painful stimuli has been reported $[37,38]$. The results reported by Defrin et al. appear to be a hybrid of what has been found in pain-free PTSD patients and PTSD-free pain patients: decreased sensitivity to nonpainful stimuli and increased hyperreactivity to painful stimuli. Sensory processing in anxiety disorders other than PTSD is believed not to differ from processing in healthy controls [35]. Another aspect of the psychobiology of pain is pain inhibition. It was found that pain inhibition is deficient in FMS patients but normal in those with depressive disorder [33]. Another study reports evidence that pain inhibition in FMS is more pronounced in 
patients with comorbid depressive symptoms compared to those with FMS alone [39]. However, due to heterogenic sample selection and different testing methods, the results in regard to pain processing and pain inhibition in chronic pain and mental disorders are inconsistent and partially contradictory [40]. Therefore, a comprehensive measurement of the clinical manifestation and psychobiological aspects of chronic pain is necessary.

To challenge the topic of a mechanism-based subgroup classification of chronic pain patients and to establish specific mechanism-based treatments [41], further variables of interest must be considered to guarantee a more holistic approach, compared to that pursued in prior research. Therefore, we developed a theoretical framework (Figure 1), which investigates the role of chemical sensitisation (nerve growth factor; NGF) [42-46], the endocannabinoid system [47,48], and other psychological variables (e.g. early stress exposure, stress and pain coping, resilience) [49-51] as well as genetic variables [52-54] in addition to mental comorbidity and psychophysiological patterns. NGF is an important key mediator of some forms of persistent pain and plays an important role in the switch from acute to chronic pain as well as the spatial spread of pain [42-46]. The endocannabinoid system refers to a group of neuromodulatory lipids that is relevant for pain memory and pain extinction $[47,48]$. Accordingly, these variables have proven to be of interest in chronic pain and to be promising in its treatment. In line with that, the current study addresses the association between the clinical manifestation of chronic musculoskeletal pain (including mental comorbidity) and neurobiological changes.

Therefore, the purpose of the present study is to 1) identify and describe subgroups of patients with musculoskeletal pain with regard to clinical manifestation (including mental comorbidity), 2) investigate whether distinct sensory profiles due to different underlying mechanisms can be distinguished in different subgroups

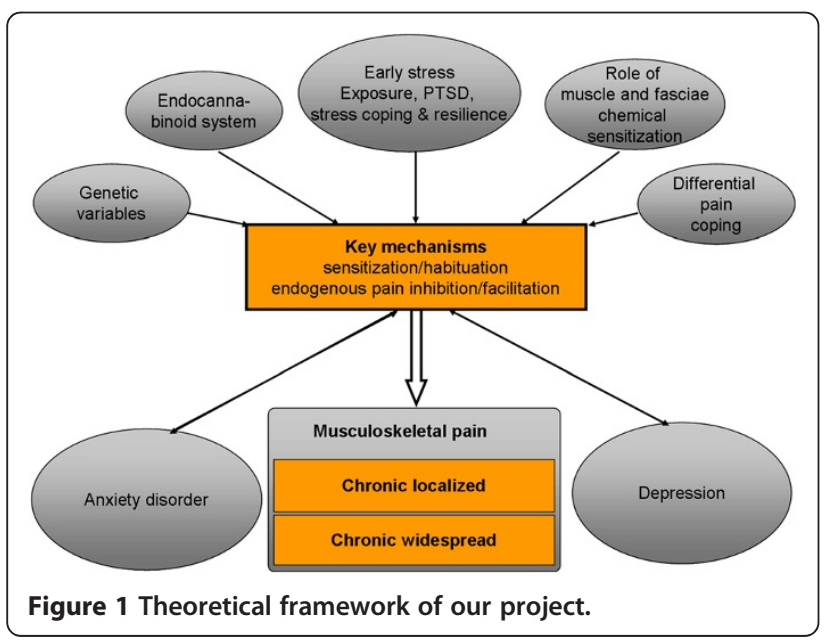

of pain patients 3) and to measure plasma nerve growth factor levels and to analyse distinct endocannabinoid profiles in different subgroups of pain patients.

\section{Methods}

This study is part of the consortium 'Localized and Generalized Musculoskeletal Pain: Psychobiological Mechanisms and Implications for Treatment (LOGIN)' funded by the German Federal Ministry of Research and Education (01EC1010A-F). More details concerning LOGIN can be found elsewhere $[55,56]$. This report focuses on subproject number six (SP6) 'Subgroups Characterised by Psychological Trauma, Mental Co-morbidity, and Psychobiological Patterns and Their Specialised Treatment'. All participants must provide written informed consent before inclusion in the study. The study has been approved by the Ethics Research Committee of the Faculty of Medicine, University of Heidelberg (S-261/ 2010) and will be carried out in compliance with the Helsinki Declaration.

\section{Design}

The study uses a descriptive and exploratory design. We will include 200 patients with chronic musculoskeletal pain from different settings (a population-based setting and a tertiary care setting) and 90 controls (pain-free patients with PTSD, depression, and healthy controls without mental disorders). All participants will undergo a physical examination. The relevant sociodemographics and measures of clinical manifestations of chronic pain are reported in Table 1: measurements of potential pathophysiological mechanisms are reported in Table 2.

\section{Samples and patient recruitment}

We will recruit patients with non-specific chronic musculoskeletal pain as well as control subjects that are not in pain: 1) Population-based sample: In a previous population-based study ("Generalization of Pain: A prospective population-based survey with clinical examination" as part of the German Back Pain Research Network, supported by the Federal Ministry of Education and Research; [21,23,57,58]), we established a representative sample of patients with chronic local and chronic widespread back-pain. For the present study, 100 patients from this representative study sample will be randomly recruited. 2) Tertiary care setting: We will recruit 100 consecutive musculoskeletal pain patients from the tertiary care Musculoskeletal Pain Centre at the University Hospital Heidelberg. 3) Control subjects: To determine whether the results are specific for pain, we will further investigate three groups of pain-free patients: a) PTSD patients $(\mathrm{n}=30)$, b) patients with depression $(\mathrm{n}=30)$, and c) healthy controls $(\mathrm{n}=30)$. Patients with PTSD and depression will 
Table 1 Variables and methods used to assess clinical manifestations of chronic non-specific musculoskeletal pain

\begin{tabular}{|c|c|}
\hline Questionnaires & Variables \\
\hline Chronic Pain Grade Questionnaire $(\mathrm{CPG})^{*}[65,66]$ & Severity of chronic pain problems (disability, pain intensity) \\
\hline Pain Experience Scale (SES) [64] & Sensory and affective descriptors of pain \\
\hline 12-Item Short-Form Health Survey (SF-12)* $[74,75]$ & Health-related quality of life \\
\hline Resilience Scale $(\mathrm{RS} 11)^{*}[97,98]$ & Resilience (personal competence, acceptance of self and life) \\
\hline Hospital Anxiety and Depression Scale (HADS-D)* $[99,100]$ & Anxiety and depression \\
\hline Childhood Trauma Questionnaire $(\mathrm{CTQ})^{*}[72,73,101]$ & $\begin{array}{l}\text { Childhood and adolescence maltreatment (physical and emotional abuse, } \\
\text { sexual abuse, physical and emotional neglect) }\end{array}$ \\
\hline Pain drawing (pain location) [62] [63] [6] & $\begin{array}{l}\text { Perceived location(s) of pain will be assessed using digitised pain drawings. } \\
\text { Classification into categories of chronic local and chronic widespread pain. }\end{array}$ \\
\hline Sociodemographics (self-report questions) & Age, sex, marital status, education, employment status \\
\hline \multicolumn{2}{|l|}{ Interviews } \\
\hline $\begin{array}{l}\text { Structured Clinical Interview for DSM-IV Axis I } \\
\text { Disorders + Axis II (SCID I+ III) [69] }\end{array}$ & DSM-IV Axis-I and Axis-II mental disorders \\
\hline \multicolumn{2}{|l|}{ Physical examination } \\
\hline $\begin{array}{l}\text { ACR Criteria for Fibromyalgia (ACR Classification) } \\
\text { [62] [102] }\end{array}$ & Tenderpoint count and documentation of specific symptoms \\
\hline Physical Impairment Scale (PIS) [67] & $\begin{array}{l}\text { Physical impairment (total flexion, total extension, average lateral flexion, } \\
\text { straight leg raising, spinal tenderness, bilateral active straight leg raising, and sit-up) }\end{array}$ \\
\hline Back Performance Scale (BPS) [68] & $\begin{array}{l}\text { Disability. Tests of daily activities (Sock Test, Pick-up Test, Roll-up Test, } \\
\text { Fingertip-to-Floor Test, and Lift Test) }\end{array}$ \\
\hline
\end{tabular}

* German Version.

be recruited in our Psychosomatic Outpatient Centre at the University Hospital of Heidelberg. Healthy controls will be recruited by flyers posted around the local community. All groups will be matched with respect to age, sex, and (if appropriate) pain location to our population-based sample. Thus, we will include at least 200 patients with non-specific chronic pain and 90 pain-free subjects.

\section{Inclusion and exclusion criteria}

The inclusion criteria for pain samples are non-specific chronic musculoskeletal pain lasting for $\geq 45$ days during the past three months, at least 18 years of age, and fluent German language skills. All control participants (participants with PTSD, depression, and healthy controls) should be pain-free. Because the point prevalence of back pain in the German population was more than one third and the 1-year prevalence was higher than $75 \%$ [57], the recruitment of patients that were absolutely pain free within the last three months, will not be feasible and will not reflect reality. Therefore, we aim to recruit only absolutely pain-free participants. If this is not possible, we will define pain-free as follows: 1) less than one day $(<24$ hours) spent in pain per week within the last three months. 2) Pain intensity $<3$ on an 11-point numeric rating scale on the days when the patient is in pain. 3) Pain does not interfere with normal activities or work. These criteria are adapted from standardised definitions

Table 2 Methods used to assess the potential mechanisms involved in chronic non-specific musculoskeletal pain

\begin{tabular}{ll}
\hline Measures & Variables \\
\hline Quantitative Sensory Testing (QST) [76,103] & $\begin{array}{l}\text { Comprehensive profiles of somatosensory functions (thermal and mechanical detection } \\
\text { and pain thresholds, vibration thresholds, and pain sensitivity to sharp and blunt } \\
\text { mechanical stimuli). Discrimination between local vs. generalised and peripheral } \\
\text { vs. central nervous mechanisms. }\end{array}$ \\
\hline $\begin{array}{ll}\text { Conditioned Pain Modulation (CPM, the diffuse } \\
\text { noxious inhibitory control-like effect) [77,78] }\end{array}$ & $\begin{array}{l}\text { A descending pain inhibitory mechanism that inhibits nociceptive activity arising from } \\
\text { the afferent primary fibres at multiple levels of the dorsal horn, resulting in diffuse pain } \\
\text { inhibition. These descending pain pathways originate from the brainstem and have } \\
\text { significant inhibitory actions on nociceptive activity, thereby affecting pain perception. }\end{array}$ \\
\hline Blood Tests & Plasma NGF levels (proximity ligand ELISA techniques) \\
\hline Endocannabinoids + related lipids (ECS) & $\begin{array}{l}\text { EC (anandamide (AEA), 2-arachidonoyl glycerol (2-AG), 1-arachidonoly glycerol (1-AG), } \\
\text { palmitoyl ethanol amine (PEA), oleoyl ethanol amine (OEA), arachidonic acid) in human } \\
\text { plasma (large- scale lipidomic profiling using the LC-MS/MS QTrap ABI5500) }\end{array}$ \\
\hline Genetics & $\begin{array}{l}\text { 2* } 9 \text { ml EDTA tubes, stored for the second funding period }\end{array}$
\end{tabular}


of back pain [59] and its recurrence [60]. Participants must also be pain free on the day of participation in the study. Patients who have a previous history of chronic pain will be excluded. Participants with PTSD and depression must fulfill DSM-IV diagnoses of the respective mental disorder. Patients with PTSD must be free of affective disorders, and patients with depression must be free of anxiety disorders. Healthy controls are not allowed to meet any DSM-IV diagnosis. The exclusion criteria are specific pathologies of CBP (e.g., spinal canal stenosis, disc hernia, spondylolisthesis, infection, malignancy, rheumatic and systematic inflammatory disorders, and fracture), sciatica pain $\geq$ than back pain, diseases affecting sensory processing (diabetes, alcohol or substance abuse, neuropathy, inflammatory diseases), pain or surgery at the dorsum of the hand or back surgery in the past three years (because the hand und back are to be subjected to investigation), and cognitive impairment.

\section{Procedure \\ Chronicity of pain}

The number of painful days in the last three months will be determined by a questionnaire and discussed with a physician to rule out misunderstandings. To be classified as suffering from chronic pain, the subject must report experiencing back pain on $\geq 45$ days in the last three months.

\section{Clinical examination}

To verify the inclusion and exclusion criteria, all participants will be questioned about their past medical history and about co-morbidities (neuropathy, diabetes, relevant alcohol consumption, infections, inflammatory diseases, disc hernia, previous severe injuries). Patients will also receive a physical examination (general, rheumatological, orthopaedic, and neurological), including blood tests (and if indicated further technical investigations such as $\mathrm{x}$-ray or MRI) with special attention paid to findings that indicate a specific origin of back pain. Therefore, the "red flags" (hints of the presence of serious pathology according to the Agency for Health Care Policy and Research Low Back Guidelines) and yellow flags will be considered [61], and former medical reports and discharge letters will be taken into account whenever available. In the case of signs of serious pathological findings, participants will be excluded, and a further investigation will be advised. Painful tender points will be identified by tenderness examination using ACR criteria [62].

\section{Measures of clinical manifestation}

The clinical manifestations of pain will be considered using the pain dimensions (pain intensity, pain location/ extent, pain quality, and pain affect), disability/ impairment (subjective as well as objective measures), and psychological measures (mental comorbidity, early life stress, health-related quality of life, and resilience). Patients will be clustered in homogeneous groups according to their clinical manifestation. In subsequent analyses, we will test whether the clinical manifestation corresponds with specific mechanisms (see below).

\section{Pain dimensions}

There are at least four dimensions of pain experience that can be distinguished. These are intensity, location, quality, and affect. Pain intensity: Pain intensity is defined as how much a person hurts. It will be measured using a numerical rating scale, ranging from 0 'no pain' to 10 'worst pain imaginable'. Pain location: Pain location can be defined as the perceived location (s) of pain sensations that patients have on or in their body. Spatial distribution patterns (local vs. referred pain) will be assessed using a digitised pain drawings [63]. Moreover, categorisation as CLP, CWP, and FMS will be based on the ACR criteria [62] and a more precise definition elaborated by Harkness et al. [6]. Therefore, each participant will be asked to complete a body pain diagram, marking all areas where pain is experienced. Afterwards, the pain diagram will be discussed jointly by the participant and the physician to rule out any misunderstandings. Pain quality and pain affect: Pain quality refers to the specific physical sensations associated with pain. Pain affect is the degree of emotional arousal caused by the sensory experience of pain. The affective and sensory dimensions of pain will be measured using the Pain Experience Scale (SES). The SES is the standard instrument of the German chapter of the International Association for the Study of Pain. The SES consists of 10 items on a sensory subscale (e.g., 'throbbing', 'wrenching' or 'stinging') and 14 items on an affective subscale (e.g., 'exhausting', 'fearful', or 'unbearable'). The response format is a four-stage format (0 'not appropriate'; 1 'somewhat appropriate'; 2 'generally appropriate'; 3 'fully appropriate'). The sensory score of the SES is the mean of all sensory items; the affective score of the SES is the mean of all affective items. The retest-reliability of the SES lies between .89 and .96, and Cronbach's Alpha lies between .72 and .92 [64].

\section{Disability/ impairment}

Chronic pain grade (CPG) The CPG assesses the severity of chronic pain problems. It measures pain intensity and disability in regard to work and daily activities via patients' self-reports. The CPG comprises 6 items that can be answered on an 11-point numerical rating scale ranging from ' 0 ' to ' 10 '. The number of days during which the patient experienced a disability during the 
past three months is assessed. Pain severity can be graded in four hierarchical classes (Grade I, low disability - low intensity; Grade II, low disability - high intensity; Grade III, high disability - moderately limiting; Grade IV, high disability - severely limiting). The CPG has proven reliability $(\alpha=.82)$ and validity $[65,66]$. To objectify impairment and disability, we will use the Physical Impairment Scale and the Back Performance Scale.

Physical impairment scale (PIS) The PIS was developed as a simple and standardised clinical observation to evaluate physical impairment in patients with chronic low back pain. The test battery combines objective physical findings indicating current functional limitations due to pain. It consists of seven tests measuring lower back movement (total flexion, total extension and average lateral flexion as measured with the inclinometer), straight leg raises, spinal tenderness and strength (bilateral active straight leg raises, sit-ups). The measurements are translated into values of 0 or 1 according to cut-off values and summed. As subjective disability in nonspecific low back pain is not explained by anatomic or structural impairment, the PIS measures functional limitation as influenced by the patient's pain behaviour. The PIS is able to discriminate between pain patients and healthy controls and is related to self-reported disability in the activities of daily living [67].

Back performance scale (BPS) The BPS is an objective clinical assessment tool that can be used to observe self-reported activity limitations in daily functioning caused by lower back pain. The BPS consists of five tests of daily activities (Sock Test, Pick-up Test, Roll-up Test, Fingertip-to-Floor Test, and Lift Test) frequently reported to be limited in back pain patients. Each performance is evaluated by the observer according to operational score definitions and then summed. The five tests are combined to obtain a performance measure of mobility-related activities requiring sagittal-plane mobility. The BPS is able to discriminate between pain patients with different return-to-work statuses and is sensitive to change. Cronbach's $\alpha$ was .73 [68].

\section{Psychological measures}

Structured clinical interview for DSM-IV (SCID) To examine the prevalence and the type of mental co-morbidity, the SCID interview, which consists of two parts, will be applied [69]. The SCID is a comprehensive and highly reliable and valid instrument [70]. The SCID-I is a semi-structured interview for the evaluation of major DSM-IV Axis-I diagnoses. With the SCID-I, it is possible to derive both a current and a previous history of psychiatric illness. The SCID-II procedure for assessing personality disorders (PD) is a two-stage process. First, subjects complete a 120-item questionnaire with questions based on the criteria from the DSM-IV. In the second stage, a semi-structured interview is administered. Positive answers must be re-evaluated by the interviewer to diagnose Axis-II PD. According to the SCID-II protocol, we will interview only those subjects who achieve the cut-off (a specified number of positive answers in a specific PD section) on the questionnaire [69]. All SKID interviews will be conducted by two psychologists with graduate training in clinical psychology. To ensure diagnostic reliability, all interviews will be audiotaped. One-fifth of the interviews will be randomly selected and rated by both psychologists. A kappa coefficient will be calculated to assess inter-rater reliability. Both psychologists will conduct 10 SKID interviews in a pilot phase. In cases of low inter-rater agreement further, training will be conducted by an experienced psychiatrist.

The Hospital Anxiety and Depression Scale (HADS-D) will be used to determine the severity of anxiety and depression. The HADS-D was especially developed for patients with somatic diseases and thus excludes physical symptoms. Each scale consists of seven items that measure anxiety and depression via the patient's selfreport with a four-stage response format. The HADS-D has good reliability (subscale depression: $\alpha=.81$; subscale anxiety: $\alpha=.80$ ) and validity [71].

Childhood Trauma Questionnaire (CTQ The German Version of the CTQ will be used to measure early stress exposure. The CTQ measures maltreatment during childhood and adolescence and will be applied because it captures factors that are relevant to chronic pain [50] that are neglected by the SKID. The CTQ consists of five subscales ('emotional abuse,' 'physical abuse', 'sexual abuse,' 'emotional neglect', and 'physical neglect'). Cronbach's $\alpha$ ranges from .89 to .96 , except for the subscale 'physical neglect' which yields an $\alpha$ of .62 [72,73].

12-Item short form health survey (SF-12) The healthrelated quality of life (HRQoL) will be measured with the SF-12. The SF-12 consists of 12 items on eight scales ('physical functioning', 'role limitations due to physical problems', 'bodily pain', 'general health', 'vitality', 'social functioning,' 'role limitations due to emotional problems', and 'perceived mental health'). Response categories vary from 2 to 6 and can be transformed to scale scores ranging from 0 ('the worst') to 100 ('the best') [74,75].

Resilience scale (RS-11) Resilience is a personality characteristic that moderates the negative effects of stress and promotes adaption. Thus it avoids any potentially negative effects of stress. Resilience will be 
measured with the RS-11. The RS-11 comprises two factors - 'acceptance of self and life' and 'personal competence' - with a seven-point response format ranging from 1 'disagree' to 7 'agree'. Thus, scores can range from seven to 77, with higher scores reflecting higher resilience. The RS-11 has very good reliability $(\alpha=.91)$.

\section{Sociodemographic variables}

Sex, age, education, employment status, marital status and further sociodemographic variables will by captured by a questionnaire.

\section{Measures of chronic pain mechanisms}

We will determine whether the patient's clinical manifestations of pain correspond with various specific potential pain mechanisms. In our study, potential mechanisms are captured through quantitative sensory testing (QST), the evaluation of conditioned pain modulation (CPM, the diffuse noxious inhibitory control-like effect), and analyses of nerve growth factor (NGF) plasma levels and endocannabinoid (ECs) profiles. Such potential mechanisms include peripheral sensitisation, central sensitisation, disinhibition, allodynia, and endogenous descending pain modulation.

\section{Psychophysiological mechanisms}

Quantitative Sensory Testing (QST) Somatosensory function will be assessed using the comprehensive QST protocol developed as part of the German Research Network on Neuropathic Pain (DFNS). Seven tests measuring 13 parameters (warm detection threshold, cold detection threshold, thermal sensory limen, paradoxical heat sensation, cold pain threshold, heat pain threshold, mechanical detection threshold, mechanical pain threshold, mechanical pain sensitivity, dynamic mechanical allodynia, windup ratio, vibration detection threshold, and pressure pain threshold) [76] will be conducted. QST testing covers all relevant aspects of the somatosensory system including large and small fibre function as well as signs of central sensitisation (dynamic tactile allodynia, punctate mechanical hyperalgesia). This way, detailed profiles of somatosensory function will be obtained for the tested body areas. The test sites will be distributed throughout the paraspinal muscles $(5 \mathrm{~cm} \pm 0.5 \mathrm{~cm}$ next to the midline on the autochthon back muscles [L1 to S1]) and on the dorsum of the ipsilateral hand.

Conditioned pain modulation (CPM) Inhibitory painmodulating mechanisms will be assessed using the CPM, a diffuse noxious inhibitory control-like effect [77-79]. The difference in pressure pain threshold (PPT) before and after the induction of DNIC by phasic heat pain (PHP) will be measured. The appropriate temperature for PHP will be determined by measurement of the heat pain threshold (HPT). The PHP will oscillate $\pm 1^{\circ} \mathrm{C}$ around the PHP-temperature. The ratings of PHP pain intensity will be assessed using a computerised Visual Analogue Scale (VAS). The HPT will be obtained using ramped stimuli $\left(1^{\circ} \mathrm{C} / \mathrm{s}, 32^{\circ} \mathrm{C}\right.$ baseline, $0^{\circ} \mathrm{C}$ and $50^{\circ} \mathrm{C}$ cutoffs, $8 \mathrm{~cm}^{2}$ thermode), which will be terminated when participants press a button. The mean of three consecutive measurements will be calculated. The PPT will be calculated as the mean of three consecutive measurements over the paraspinal muscles $(5 \mathrm{~cm} \pm 0.5 \mathrm{~cm}$ next to the midline on the autochthon back muscles [L1 to S1]; site contralateral to the QST).

\section{Neurobiological measures}

Nerve growth factor (NGF) NGF levels in human blood samples will be determined using proximity ligand Elisa techniques. Endocannabinoids (ECs): EC (anandamide (AEA), 2-arachidonoyl glycerol (2-AG), 1-arachidonoly glycerol (1-AG), palmitoyl ethanol amine (PEA), oleoyl ethanol amine (OEA), arachidonic acid) analyses of human blood samples will be performed by large-scale lipidomic profiling using the LC-MS/MS QTrap ABI5500. All analyses of NGF and ECs will be performed in collaboration with our consortium partners.

\section{Sample size estimation}

A sample of more than 200 musculoskeletal pain patients (population-based sample and tertiary care sample) will be acceptable in order to recruit a sufficient number of "cases" with different clinical manifestations (e.g., local vs. generalised pain, different levels of pain affect, anxiety disorders, mood disorders, no mental comorbidity). To estimate the number of patients in different subgroups, we will refer to data from our population-based study. Approximately 61.8\% of the patients in our population-based study had chronic local pain (CLP), and 38.2\% had chronic widespread pain (CWP). We also found a prevalence of $12.7 \%$ for depression and $20.9 \%$ for anxiety disorders (using the SCID-I). The prevalence of depression and anxiety may be higher in a tertiary care pain setting, as reported by others $[80,81]$. Therefore, we expect group sizes that will be sufficient to gather abundant information regarding clinical manifestations. We also consulted recent QST studies and a review regarding DNIC to estimate the required group sizes. For DNIC testing, a systematic review [82] evaluated studies with an average group size of 20. A group size of 20 to 30 is also commonly used in recent QST studies $[21,63,83]$. We therefore expect our group sizes to be appropriate for the investigation of distinct sensory profiles. Studies investigating endocannabinoids used sample sizes between $n=10$ and $n=20$ patients per 
group and reported mean effect sizes between .60 and .80 (e.g. [84,85]). Studies with NGF have reported effect sizes between 2.02 and 4.31 [44,86]. With regard to pain mechanisms, small sample sizes are sufficient to compare subgroups. This will also apply for the groups of pain-free patients with PTSD, depression, and healthy controls (each $\mathrm{n}=30$, respectively).

\section{Quality assurance}

To ensure that the measurements are reliable and high in quality, the project will have a pilot phase. In this pilot phase the study staff will be trained in the study procedures (if necessary) and conduct paired measurements to ensure reliability and validity. The pilot phase will be finished when the reliability and validity of the measurements has been verified. The study protocols will be tested and adapted if necessary.

\section{Statistical analyses}

Descriptive statistics will be presented with means and standard deviations for continuous variables and absolute numbers and percentages for categorical variables. Questionnaires will be dealt with according to questionnaire manuals. The prevalence of chronic local pain, chronic widespread pain, fibromyalgia, and mental comorbidities will be determined for the populationbased sample and tertiary care setting. Explorative cluster analysis will be conducted to establish subgroups based on the clinical manifestations observed. Therefore, the dimensions of pain (see above) and mental comorbidity will be used as cluster variables. Then, we will explore whether different neurobiological profiles (QST profiles, CPM, NGF levels, EC profiles) correspond with these subgroups. Pain drawings will be scanned, superimposed, and transformed into two-dimensional color-coded images. Body areas with high occurrence of pain will be illustrated in dark red; body areas without pain will appear in white. To classify patients who suffer chronic local pain (CLP) or chronic widespread pain (CWP), pain drawings will be analysed according to the ACR criteria [62] and a more precise definition [6]. Quantitative sensory testing (QST) data pre-processing and statistical analysis will be performed according to the protocol established by Rolke et al. [76]. To quantify conditioned pain modulation (CPM), the PPT before PHP will be subtracted from the PPT after PHP. Negative values indicate an analgesic effect due to CPM. Differences between patient groups will be analysed using analyses of co-variance (ANCOVA), followed by Fisher's least significant difference test. Potential confounders will be included as covariates, if indicated. QST modalities or CPM will be entered as dependent variables, the patient groups as an independent variable. For more detailed information analysing QST data, we will refer to the protocol proposed by Rolke et al. [76]. The same procedure will be applied with regard to nerve growth factor (NGF) and endocannabinoids (ECs).

\section{Discussion}

Establishment of a mechanism-based subgroup classification of pain and the development of specific treatments were suggested almost a decade ago [41]. Since then, the topic has been discussed amid controversy $[19,22,87,88]$. Small effect sizes of chronic pain treatments were suspected to be due to unspecific treatment approaches, but different pain generating and maintaining mechanisms $[19,20]$. This possibly is also supported by clinical experience, which shows that the subgroups of chronic pain patients are heterogeneous, even if suffering the same disease like non-specific chronic back pain. However, only a few studies have aimed to identify different pain mechanisms [20,21]. The identification of patient subgroups is needed if we wish to establish distinct pathophysiological mechanisms and targets that are necessary for the development of new analgesic drugs and non-pharmacological mechanism-based treatment options. There is a corresponding lack of evidence for subgroup-specific treatments.

In addition to the identification of specific pathophysiological mechanisms, we will implement a feasibility study that is designed as a randomised controlled trial. We will adapt the proven Eye-MovementDesensitization-Reprocessing (EMDR) short-time therapy to the subgroup of patients with chronic pain who have experienced psychological trauma. This approach might be promising because EMDR is an effective treatment for patients with PTSD $[89,90]$ or chronic pain [91-94] but has not yet been adapted to patients with chronic musculoskeletal pain who have experienced psychological trauma. However, there are initial signs that this might be a promising approach $[95,96]$. To identify potential underlying mechanisms, we will use all measurements of our study obtained before and after treatment (plus functional magnetic resonance imaging). Thus, our study will foster the development of new, more specific interventions for chronic pain patients.

The remaining challenge is to match a sign or symptom to a mechanism, but a sign or symptom could potentially be produced by several distinct mechanisms $[19,20]$. The novel aspect of our research is therefore its comprehensive approach that uses reliable and valid diagnostic tools. This approach comprises many variables that have been shown to be involved in alterations in sensory processing (e.g., mental comorbidity, descending pain modulating systems, nerve growth factor, endocannabinoids). A holistic approach is also needed because research shows that these variables influence each other [35]. The observed alterations might be 
hybrids of alterations caused by single variables $[21,37]$. The inclusion of a population-based sample is also reasonable because prior research is usually based on highly selective clinical samples of pain patients, and this might bias research. Notably, the study is part of the LOGIN consortium. LOGIN comprises seven subprojects and includes basic and applied research in animals and humans as well as preclinical and clinical projects. All projects will use a core set of variables that investigates similar pathogenetic mechanisms. This approach enables LOGIN to study aspects in animals that cannot be investigated in humans (e.g., pathophysiological processes in the spinal cord or brain) and to transfer results to the human subprojects and vice versa. This approach will be fostered by the translational aspects of LOGIN. Thus, using the synergy of the different subprojects, the contemporary translation, implementation and dissemination of the results will be guaranteed.

\section{Competing interest}

The authors declare that they have no competing interests.

\section{Author's contributions}

AG has made substantial contributions to conception and design and has drafted the manuscript. He also participates in data collection, analyses of the data, and coordinates the project. JT has made substantial contributions to conception and design and revised the manuscript critically for important intellectual content. He also participates in data collection. $\mathrm{MH}$ and WE have made substantial contributions to conception and design and revised the manuscript critically for important intellectual content. SJ and SL participate in data collection and analyses of the data. GS revised the manuscript critically for important intellectual content. All authors read and approved the final version of the manuscript to be published.

\section{Acknowledgements}

The project is part of the research Consortium LOGIN: "Localized and Generalized Musculoskeletal Pain: Psychobiological Mechanisms and Implications for Treatment" funded by the German Federal Ministry of Education and Research (BMBF, 01EC1010A-E). We thank the members of the consortium LOGIN for their scientific thoughts and constructive discussions in the development of this project. This study is supported by a research grant from the BMBF, project 01EC1010A.

Received: 1 June 2012 Accepted: 23 July 2012

Published: 3 August 2012

\section{References}

1. Maetzel A, Li L: The economic burden of low back pain: a review of studies published between 1996 and 2001. Best Pract Res Clin Rheumatol 2002, 16:23-30.

2. Maschewsky-Schneider U, Klärs G, Ryl L, Sewöster D, Starker A, Saß AC: Ergebnisse der Kriterienanalyse für die Auswahl eines neuen Gesundheitsziels in Deutschland. Bundesgesundheitsblatt Gesundheitsforschung - Gesundheitsschutz 2009, 52:764-774. gesundheitsziele.de.

3. Ricci JA, Stewart WF, Chee E, Leotta C, Foley K, Hochberg MC: Back pain exacerbations and lost productive time costs in United States workers. Spine 2006, 31:3052-3060.

4. Cimmino MA, Ferrone C, Cutolo M: Epidemiology of chronic musculoskeletal pain. Best Pract Res Clin Rheumatol 2011, 25:173-183.

5. Freburger JK, Holmes GM, Agans RP, Jackman AM, Darter JD, Wallace AS, Castel LD, Kalsbeek WD, Carey TS: The rising prevalence of chronic low back pain. Arch Intern Med 2009, 169:251-258.

6. Harkness EF, Macfarlane GJ, Silman AJ, McBeth J: Is musculoskeletal pain more common now than 40 years ago? Two population-based crosssectional studies. Rheumatology 2005, 44:890-895.
7. Ekman $M$, Jönhagen $S$, Hunsche $E$, Jönsson L: Burden of illness of chronic low back pain in sweden: a cross-sectional, retrospective study in primary care setting. Spine 2005, 30:1777-1785.

8. Depont F, Hunsche E, Abouelfath A, Diatta T, Addra I, Grelaud A, Lagnaoui R, Molimard M, Moore N: Medical and non-medical direct costs of chronic low back pain in patients consulting primary care physicians in France. Fundam Clin Pharmacol 2010, 24:101-108.

9. Kalauokalani D, Cherkin DC, Sherman KJ, Koepsell TD, Deyo RA: Lessons from a trial of acupuncture and massage for low back pain: patient expectations and treatment effects. Spine 2001, 26:1418-1424.

10. Karjalainen KA, Malmivaara A, van Tulder MW, Roine R, Jauhiainen M, Hurri $H$, Koes BW: Multidisciplinary rehabilitation for fibromyalgia and musculoskeletal pain in working age adults. Cochrane Database Syst Rev 1999, 3:CD001984.

11. O'Brien EM, Staud RM, Hassinger AD, McCulloch RC, Craggs JG, Atchison JW, Price DD, Robinson ME: Patient-centered perspective on treatment outcomes in chronic pain. Pain Med 2010, 11:6-15.

12. Robinson ME, Brown JL, George SZ, Edwards PS, Atchison JW, Hirsh AT, Waxenberg LB, Wittmer V, Fillingim RB: Multidimensional success criteria and expectations for treatment of chronic pain: the patient perspective. Pain Med 2005, 6:336-345.

13. Stein $\mathrm{C}$, Reinecke $\mathrm{H}$, Sorgatz $\mathrm{H}$ : Opiod use in chronic noncancer pain: guidelines revisited. Curr Opin Anesthesiol 2010, 23:598-601.

14. Reinecke H, Sorgatz H: S-3-Leitlinie LONTS. Der Schmerz 2009, 23:440-447.

15. Machado LAC, Kamper SJ, Herbert RD, Maher CG, McAuley JH: Analgesic effects of treatments for non-specific low back pain: a meta-analysis of placebo-controlled randomized trials. Rheumatology 2009, 48:520-527.

16. Keller A, Hayden J, Bombardier C, van Tulder M: Effect sizes of non-surgical treatments of non-specific low-back pain. Eur Spine J 2007, 16:1776-1788.

17. Natvig B, Bruusgaard D, Eriksen W: Localized low back pain and low back pain as part of widespread musculoskeletap pain: two different disorders? A cross-sectional population study. J Rehabil Med 2001, 33:21-25.

18. Raspe A, Matthis C, Héon-Klin V, Raspe H: Chronic back pain: more than pain in the back? Findings of a regional survey among insurees of a workers pension insurance fund. Rehabilitation (Stuttg) 2003, 42:195-203.

19. Woolf CJ, Mannion RJ: Neuropathic pain: aetiology, symptoms, mechanisms, and management. The Lancet 1999, 353:1959-1964.

20. Maier C, Baron R, Tölle TR, Binder A, Birbaumer N, Birklein F, Gierthmühlen J, Flor H, Geber C, Huge V, Krumova EK, Landwehrmeyer GB, Magerl W, Maihöfner C, Richter H, Rolke R, Scherens A, Schwarz A, Sommer C, Tronnier V, Üçeyler N, Valet M, Wasner G, Treede RD: Quantitative sensory testing in the German Research Network on Neuropathic Pain (DFNS): somatosensory abnormalities in 1236 patients with different neuropathic pain syndromes. Pain 2010, 150:439-450.

21. Blumenstiel K, Gerhardt A, Rolke R, Bieber C, Tesarz J, Friederich H-C, Eich W, Treede R-D: Quantitative sensory testing profiles in chronic back pain are distinct from those in fibromyalgia. Clin J Pain 2011, 27:682-690.

22. Jensen TS, Baron R: Translation of symptoms and signs into mechanisms in neuropathic pain. Pain 2003, 102:1-8.

23. Gerhardt A, Hartmann M, Schuller-Roma B, Blumenstiel K, Bieber C, Eich W, Steffen S: The prevalence and type of Axis-I and Axis-II mental disorders in subjects with non-specific chronic back pain: results from a population-based study. Pain Med 2011, 12:1231-1240.

24. Demyttenaere K, Bruffaerts R, Lee S, Posada-Villa J, Kovess V, Angermeyer MC, Levinson D, de Girolamo G, Nakane H, Mneimneh Z, Lara C, de Graaf R, Scott KM, Gureje O, Stein DJ, Haro JM, Bromet EJ, Kessler RC, Alonso J, Von Korff M: Mental disorders among persons with chronic back or neck pain: results from the world mental health surveys. Pain 2007, 129:332-342.

25. Benjamin S, Morris S, McBeth J, Macfarlane GJ, Silman AJ: The association between chronic widespread pain and mental disorder: a populationbased study. Arthritis \& Rheum 2000, 43:561-567.

26. Uguz F, Çiçek E, Salli A, Karahan AY, Albayrak I, Kaya N, Ugurlu H: Axis I and Axis II psychiatric disorders in patients with fibromyalgia. Gen Hosp Psychiatry 2010, 32:105-107.

27. Sharp TJ: The prevalence of post-traumatic stress disorder in chronic pain patients. Curr Pain Headache Rep 2004, 8:111-115.

28. de Leeuw R, Bertoli E, Schmidt JE, Carlson CR: Prevalence of post-traumatic stress disorder symptoms in orofacial pain patients. Oral Surg Oral Med Oral Pathol Oral Radiol Endod 2005, 99:558-568. 
29. Amital D, Fostick L, Polliack ML, Segev S, Zohar J, Rubinow A, Amital H: Posttraumatic stress disorder, tenderness, and fibromyalgia syndrome: are they different entities? J Psychosom Res 2006, 61:663-669.

30. Sledjeski EM, Speisman B, Dierker LC: Does number of lifetime traumas explain the relationship between PTSD and chronic medical conditions? Answers from the National Comorbidity Survey-Replication (NCS-R) J Behav Med 2008, 31:341-349.

31. Young Casey C, Greenberg MA, Nicassio PM, Harpin RE, Hubbard D: Transition from acute to chronic pain and disability: a model including cognitive, affective, and trauma factors. Pain 2008, 134:69-79.

32. Klauenberg S, Maier C, Assion H-J, Hoffmann A, Krumova EK, Magerl W, Scherens A, Treede R-D, Juckel G: Depression and changed pain perception: hints for a central disinhibition mechanism. Pain 2008 140:332-343.

33. Normand E, Potvin S, Gaumond I, Cloutier G, Corbin JF, Marchand S: Pain inhibition is deficient in chronic widespread pain but normal in major depressive disorder. J Clin Psychiatry 2011, 72:219-224.

34. Jensen KB, Petzke F, Carville S, Fransson P, Marcus H, Williams SCR, Choy E, Mainguy $Y$, Gracely $R$, Ingvar $M$, Kosek E: Anxiety and depressive symptoms in fibromyalgia are related to poor perception of health but not to pain sensitivity or cerebral processing of pain. Arthritis \& Rheum 2010, 62:3488-3495.

35. Defrin R, Ginzburg K, Solomon Z, Polad E, Bloch M, Govezensky M, Schreiber S: Quantitative testing of pain perception in subjects with PTSD Implications for the mechanism of the coexistence between PTSD and chronic pain. Pain 2008, 138:450-459.

36. Henriksson KG: Hypersensitivity in muscle pain syndromes. Curr Pain Headache Rep 2003, 7:426-432.

37. Geuze E, Westenberg HGM, Jochims A, de Kloet CS, Bohus M, Vermetten E, Schmahl C: Altered pain processing in veterans with posttraumatic stress disorder. Arch Gen Psychiatry 2007, 64:76-85

38. Kraus A, Geuze E, Schmahl C, Greffrath W, Treede R-D, Bohus M, Vermetten E: Differentiation of pain ratings in combat-related posttraumatic stress disorder. Pain 2009, 143:179-185.

39. de Souza JB, Potvin S, Goffaux P, Charest J, Marchand S: The deficit of pain inhibition in fibromyalgia is more pronounced in patients with comorbid depressive symptoms. Clin J Pain 2009, 25:123-127.

40. Moeller-Bertram T, Keltner J, Strigo IA: Pain and post traumatic stress disorder - Review of clinical and experimental evidence. Neuropharmacology 2012, 62:586-597.

41. Woolf CJ, Bennett GJ, Doherty M, Dubner R, Kidd B, Koltzenburg M, Lipton $R$, Loeser JD, Payne $R$, Torebjork E: Towards a mechanism-based classification of pain? Pain 1998, 77:227-229.

42. Sarchielli P, Mancini ML, Floridi A, Coppola F, Rossi C, Nardi K, Acciarresi M, Pini LA, Calabresi P: Increased levels of neurotrophins are not specific for chronic migraine: evidence from primary fibromyalgia syndrome. J Pain 2007, 8:737-745.

43. Seidel MF, Herguijuela M, Forkert R, Otten U: Nerve growth factor in rheumatic diseases. Semin Arthritis Rheum 2010, 40:109-126.

44. Rukwied R, Mayer A, Kluschina O, Obreja O, Schley M, Schmelz M: NGF induces non-inflammatory localized and lasting mechanical and thermal hypersensitivity in human skin. Pain 2010, 148:407-413.

45. Sugiura A, Ohtori S, Yamashita M, Inoue G, Yamauchi K, Koshi T, Suzuki M, Norimoto M, Orita S, Eguchi Y, Takahashi Y, Watanabe TS, Ochiai N, Takaso $M$, Takahashi $K$ : Existence of nerve growth factor receptors, tyrosine kinase a and p75 neurotrophin receptors in intervertebral discs and on dorsal root ganglion neurons innervating intervertebral discs in rats. Spine 2008, 33:2047-2051.

46. Yamauchi K, Inoue G, Koshi T, Yamashita M, Ito T, Suzuki M, Equchi Y, Orita S, Takaso M, Nakagawa K, Aoki Y, Ochiai N, Kishida S, Endo M, Yamashita T, Takahashi K, Ohtori S: Nerve growth factor of cultured medium extracted from human degenerative nucleus pulposus promotes sensory nerve growth and induces substance $P$ in vitro. Spine 2009, 34:2263-2269.

47. Abrams DI, Couey P, Shade SB, Kelly ME, Benowitz NL: Cannabinoid-opioid interaction in chronic pain. Clin Pharmacol Ther 2011, 90:844-851.

48. Burstein S, Zurier R: Cannabinoids, endocannabinoids, and related analogs in inflammation. The AAPS Journal 2009, 11:109-119.

49. Jones EA, McBeth J, Nicholl B, Morriss RK, Dickens C, Jones GT, Macfarlane GJ: What characterizes persons who do not report musculoskeletal pain? Results from a 4-year population-based longitudinal study (The Epifund Study). J Rheumatol 2009, 36:1071-1077.
50. Häuser W, Kosseva M, Üceyler N, Klose P, Sommer C: Emotional, physical, and sexual abuse in fibromyalgia syndrome: a systematic review with meta-analysis. Arthritis Care Res 2011, 63:808-820.

51. Alschuler KN, Otis JD: Coping strategies and beliefs about pain in veterans with comorbid chronic pain and significant levels of posttraumatic stress disorder symptoms. Eur J Pain 2012, 16:312-319.

52. LaCroix-Fralish ML, Austin J-S, Zheng FY, Levitin DJ, Mogil JS: Patterns of pain: meta-analysis of microarray studies of pain. Pain 2011, 152:1888-1898.

53. Williams FMK, Spector TD, MacGregor AJ: Pain reporting at different body sites is explained by a single underlying genetic factor. Rheumatology 2010, 49:1753-1755

54. Costigan M, Belfer I, Griffin RS, Dai F, Barrett LB, Coppola G, Wu T, Kiselycznyk C, Poddar M, Lu Y, Diatchenko L, Smith S, Cobos EJ, Zaykin D, Allchorne A, Shen P-H, Nikolajsen L, Karppinen J, Männikkö M, Kelempisioti A, Goldman D, Maixner W, Geschwind DH, Max MB, Seltzer Z, Woolf CJ: Multiple chronic pain states are associated with a common amino acid-changing allele in KCNS1. Brain 2010, 133:2519-2527.

55. LOGIN - Localized and generalized musculoskelettal pain: psychobiological mechanisms and implications for treatment. http://www.login-verbund.de/ index.php?id $=2 \& L=1$

56. Viniol A, Jegan N, Leonhardt C, Strauch K, Brugger M, Barth J, Baum E, Becker A: Study protocol: transition from localized low back pain to chronic widespread pain in general practice: identification of risk factors, preventive factors and key elements for treatment - A cohort study. BMC Musculoskelet Disord 2012, 13:77.

57. Schmidt CO, Raspe H, Pfingsten M, Hasenbring M, Basler HD, Eich W, Kohlmann T: Back pain in the german adult population: prevalence, severity, and sociodemographic correlates in a multiregional survey. Spine 2007, 32:2005-2011.

58. Schmidt CO, Raspe H, Pfingsten M, Hasenbring M, Basler HD, Eich W, Kohlmann T: Does attrition bias longitudinal population-based studies on back pain? Eur J Pain 2011, 15:84-91.

59. Dionne CE, Dunn KM, Croft PR, Nachemson AL, Buchbinder R, Walker BF Wyatt M, Cassidy JD, Rossignol M, Leboeuf-Yde C, Hartvigsen J, Leino-Arjas P, Latza U, Reis S: Gil del Real MT, Kovacs FM, Öberg B, Cedraschi C, Bouter LM, Koes BW, Picavet HSJ, van Tulder MW, Burton K, Foster NE, Macfarlane GJ, Thomas E, Underwood M, Waddell G, Shekelle P, Volinn $\mathrm{E}$, et al: A consensus approach toward the standardization of back pain definitions for use in prevalence studies. Spine 2008, 33:95-103.

60. Stanton TR, Latimer J, Maher CG, Hancock MJ: A modified Delphi approach to standardize low back pain recurrence terminology. Eur Spine J 2011, 20:744-752.

61. Rubinstein SM, van Tulder M: A best-evidence review of diagnostic procedures for neck and low-back pain. Best Pract Res Clin Rheumatol 2008, 22:471-482

62. Wolfe F, Smythe HA, Yunus MB, Bennett RM, Bombardier C, Goldenberg DL, Tugwell P, Campbell SM, Abeles M, Clark P, Fam AG, Farber SJ, Fiechtner JJ: Michael Franklin C, Gatter RA, Hamaty D, Lessard J, Lichtbroun AS, Masi AT, McCain GA, John Reynolds W, Romano TJ, Jon Russell I, Sheon RP: The American College of Rheumatology 1990 criteria for the classification of fibromyalgia. Arthritis \& Rheum 1990, 33:160-172.

63. Pfau DB, Rolke R, Nickel R, Treede R-D, Daublaender M: Somatosensory profiles in subgroups of patients with myogenic temporomandibular disorders and fibromyalgia syndrome. Pain 2009, 147:72-83.

64. Geissner E: Die Schmerzempfindungsskala (SES). Göttingen: Hogrefe Verlag; 1996.

65. Klasen BW, Hallner D, Schaub C, Willburger R, Hasenbring M: Validation and reliability of the German version of the Chronic Pain Grade questionnaire in primary care back pain patients. Psychosoc Med 2004, 1: Doc7

66. Von Korff M, Ormel J, Keefe FJ, Dworkin SF: Grading the severity of chronic pain. Pain 1992, 50:133-149.

67. Waddell G, Somerville D, Henderson I, Newton M: Objective clinical evaluation of physical impairment in chronic low back pain. Spine 1992, 17:617-628.

68. Strand LI, Moe-Nilssen R, Ljunggren AE: Back Performance Scale for the assessment of mobility-eelated activities in people with back pain. Phys Ther 2002, 82:1213-1223. 
69. Wittchen HU, Zaudig M, Fydrich T: SKID-I u. II: Strukturiertes Klinisches Interview für DSM-IV. Achse I: Psychische Störungen. Göttingen: Hogrefe Verlag für Psychologie 1997.

70. What is the reliability of the SCID? Oficial web site for the Structured Clinical Interview for DSM disorders SCID. http://cpmenet.columbia.edu/dept/scid/ psychometric/scidll_reliability.html.

71. Hermann C, Buss U: Snaith RP: Hospital Anxiety and Depression ScaleDeutsche Version. Verlag Hans Huber: Ein Fragebogen zur Erfassung von Angst und Depressivität in der somatischen Medizin Bern; 2011.

72. Wingenfeld K, Spitzer C, Mensebach C, Grabe HJ, Hill A, Gast U, Schlosser N, Höpp H, Beblo T, Driessen M: Die deutsche Version des Childhood Trauma Questionnaire (CTQ): Erste Befunde zu den psychometrischen Kennwerten. Psychother Psych Med 2010, 60:442-450.

73. Bernstein DP, Stein JA, Newcomb MD, Walker E, Pogge D, Ahluvalia T, Stokes J, Handelsman L, Medrano M, Desmond D, Zule W: Development and validation of a brief screening version of the Childhood Trauma Questionnaire. Child Abuse Negl 2003, 27:169-190.

74. Ware JEJ, Kosinski M, Keller SD: A 12-Item Short-Form Health Survey: Construction of scales and preliminary tests of reliability and validity. Med Care 1996, 34:220-233.

75. Bullinger M, Kirchberger I: SF-36 Fragebogen zum Gesundheitszustand: Handanweisung. Göttingen: Hogrefe; 1998.

76. Rolke R, Magerl W, Campbell KA, Schalber C, Caspari S, Birklein F, Treede RD: Quantitative sensory testing: a comprehensive protocol for clinical trials. Eur J Pain 2006, 10:77-88.

77. Le Bars D, Dickenson AH, Besson J-M: Diffuse Noxious Inhibitory Controls (DNIC). II. Lack of effect on non-convergent neurones, supraspinal involvement and theoretical implications. Pain 1979, 6:305.

78. Le Bars D: Dickenson AH, Besson J-M: Diffuse noxious inhibitory controls (DNIC). I. Effects on dorsal horn convergent neurones in the rat. Pain 1979, 6:283-304.

79. Yarnitsky D, Arendt-Nielsen L, Bouhassira D, Edwards RR, Fillingim RB, Granot M, Hansson P, Lautenbacher S, Marchand S, Wilder-Smith O: Recommendations on terminology and practice of psychophysical DNIC testing. Eur J Pain 2010, 14:339-339.

80. Benjamin S, Barnes D, Berger S, Clarke I, Jeacock J: The relationship of chronic pain, mental illness and organic disorders. Pain 1988, 32:185-195.

81. Asmundson GJG, Coons MJ, Taylor S, Katz J: PTSD and the experience of pain: research and clinical implications of shared vulnerability and mutual maintenance models. Can J Psychiatry 2002, 47:930-937.

82. Pud D, Granovsky Y, Yarnitsky D: The methodology of experimentally induced diffuse noxious inhibitory control (DNIC)-like effect in humans. Pain 2009, 144:16-19.

83. Bachmann CG, Rolke R, Scheidt U, Stadelmann C, Sommer M, Pavlakovic G, Happe S, Treede R-D, Paulus W: Thermal hypoaesthesia differentiates secondary restless legs syndrome associated with small fibre neuropathy from primary restless legs syndrome. Brain 2010, 133:762-770.

84. Blüher M, Engeli S, Klöting N, Berndt J, Fasshauer M, Bátkai S, Pacher $P$, Schön MR, Jordan J, Stumvoll M: Dysregulation of the peripheral and adipose tissue endocannabinoid system in human abdominal obesity. Diabetes 2006, 55:3053-3060.

85. Di Marzo V, Verrijken A, Hakkarainen A, Petrosino S, Mertens I, Lundbom N, Piscitelli F, Westerbacka J, Soro-Paavonen A, Matias I, Van Gaal L, Taskinen $M-R$ : Role of insulin as a negative regulator of plasma endocannabinoid levels in obese and nonobese subjects. Eur J Endocrinol 2009, 161:715-722.

86. Toyoda M, Nakamura M, Makino T, Hino T, Kagoura M, Morohashi M: Nerve growth factor and substance $\mathrm{P}$ are useful plasma markers of disease activity in atopic dermatitis. Br J Dermatol 2002, 147:71-79.

87. Turk DC: The potential of treatment matching for subgroups of patients with chronic pain: lumping versus splitting. Clin J Pain 2005, 21:44-55.

88. Wand B, O'Connell N: Chronic non-specific low back pain - sub-groups or a single mechanism? BMC Musculoskelet Disord 2008, 9:11.

89. Bisson J, Andrew M: Psychological treatment of post-traumatic stress disorder (PTSD). The Cochrane Library 2007, CD003388.

90. Flatten G, Gast U, Hofmann A, Knaevelsrud C, Lampe A, Liebermann P, Maercker A, Reddemann L, Wöller W: S 3- Leitlinie posttraumatische Belastungsstörung. Trauma \& Gewalt 2011, 3:202-210.

91. Schneider J, Hofmann A, Rost C, Shapiro F: EMDR in the treatment of chronic phantom limb pain. Pain Med 2008, 9:76-82.
92. de Roos C, Veenstra AC: EMDR pain protocol fur current pain. In Eye Movement Desensitization and Reprocessing (EMDR): Special populations. Edited by Luber M. New York: Springer; 2009.

93. Grant M: Pain Control with EMDR. 3rd edition. Charleston: South Carolina: Createspace; 2009.

94. Grant M, Threlfo C: EMDR in the treatment of chronic pain. J Clin Psychol 2002, 58:1505-1520.

95. Grant M: EMDR: a new treatment for trauma and chronic pain. Complement Ther Nurs Midwifery 2000, 6:91-94.

96. de Roos C, Veenstra AC, de Jongh $A$, den Hollander-Gijsman M, van der Wee NJ, Zitman FG, van Rood YR: Treatment of chronic phantom limb pain using a trauma-focused psychological approach. Pain Res Manag 2010, 15:65-71.

97. Wagnild GM, Young HM: Development and psychometric evaluation of the Resilience Scale. J Nurs Meas 1993, 1:165-178.

98. Schumacher J, Leppert K, Gunzelmann T, Strauß B, Brähler E: Die Resilienzskala - Ein Fragebogen zur Erfassung der psychischen Widerstandsfähigkeit als Personmerkmal. Z Klin Psychol Psychiatr Psychother 2005, 53:16-39.

99. Zigmond AS, Snaith RP: The hospital anxiety and depression scale. Acta Psychiatr Scand 1983, 67:361-370.

100. Herrmann C, Buss U: Snaith RP: Hospital Anxiety and Depression Scale - Deutsche Version (HADS-D). Verlag Hans Huber: Ein Fragebogen zur Erfassung von Angst und Depressivität in der somatischen Medizin. Testdokumentation und Handanweisung. Bern; 1995.

101. Bernstein DP, Fink L, Handelsman L, Foote J, Lovejoy M, Wenzel K, Sapareto E, Ruggiero J: Initial reliability and validity of a new retrospective measure of childhood abuse and neglect. Am J Psychiatry 1994, 151:1132-1136.

102. Wolfe F: New American College of Rheumatology criteria for fibromyalgia: a twenty-year journey. Arthritis Care Res 2010, 62:583-584

103. Rolke R, Baron R, Maier C, Tölle TR, Treede RD, Beyer A, Binder A, Birbaumer N, Birklein F, Bötefür IC, Braune S, Flor H, Huge V, Klug R, Landwehrmeyer GB, Magerl W, Maihöfner C, Rolko C, Schaub C, Scherens A, Sprenger T, Valet M, Wasserka B: Quantitative sensory testing in the German Research Network on Neuropathic Pain (DFNS): standardized protocol and reference values. Pain 2006, 123:231-243.

doi:10.1186/1471-2474-13-136

Cite this article as: Gerhardt et al:: Subgroups of musculoskeletal pain patients and their psychobiological patterns - The LOGIN study protocol. BMC Musculoskeletal Disorders 2012 13:136.

\section{Submit your next manuscript to BioMed Central and take full advantage of:}

- Convenient online submission

- Thorough peer review

- No space constraints or color figure charges

- Immediate publication on acceptance

- Inclusion in PubMed, CAS, Scopus and Google Scholar

- Research which is freely available for redistribution 